\title{
Website accessibility statements: a comparative investigation of local government and high street sectors
}

\author{
Catherine M. Parkinson
}

\begin{abstract}
A detailed comparison of the use, nature and contents of the website accessibility statements of local government and high street sectors was undertaken. 55 local government and 55 high street websites were examined in depth using a checklist questionnaire to establish the presence or absence of a statement, the prominence of the statement on the website, the accessibility of the statement page, the contents of the statement, the audience of the statement and the role that the statement performed.

The research found that there were considerable differences in the presence, execution and quality of accessibility statements between the two sectors. It also found a wide variation in the contents of the statements, the roles that they adopted and the audience that they were written for. The research findings led to the development of some recommendations for how to write an effective accessibility statement and suggestions for further research.
\end{abstract}

\section{Introduction}

Accessibility statements are the declarations on a website, produced by the web developer or organisation that the website represents, about the accessibility of the website to disabled people and others with accessibility needs. Although they can take different forms, they are most often a single page or group of pages entitled 'accessibility' or 'accessibility help' or 'help for people with disabilities'. The accessibility statement on a website can reveal something about the web developer and organisation's attitudes to disabled people and accessibility, their understanding of and commitment to web accessibility design issues and the methods by which they have tried to address the issue of making their website

\section{Author}

Catherine Parkinson graduated from Loughborough University in 2006 with an MA (distinction) in Information and Library Management. She was the Information Officer for the disability charity Leicestershire CIL, and is now working at the Research School of Informatics at Loughborough University.

Email: catherine_parkinson@hotmail.com 
accessible. Accessibility statements can provide the opportunity for the web developer or organisation to offer practical help to people who may encounter barriers in using the website; they can become an important tool to aid effective use of the site and a further means of making a website more accessible.

This research study focused on a detailed, comparative analysis of two samples of accessibility statements. Samples were taken from the websites of local government organisations and also from 'high street' organisations, which included retail and financial websites. The choice of these two samples offered an interesting opportunity for comparison of website accessibility statements in the public and private sectors. Both of these sectors have obligations under the Disability Discrimination Act Part 3: Goods, Facilities and Services (Great Britain, 1995) to make their websites accessible, and both make their services available online - local government sites offer the opportunity to conduct essential transactions online and high street sites offer online shopping and banking opportunities. The study aimed to examine and compare the website accessibility statements of these two sectors in order to better understand current practice and usage, generate recommendations for best practice and raise issues and questions about accessibility statements that further research could address.

\section{Methodology}

The methodology chosen to examine the accessibility statements was the application of a checklist of questions to a large sample of statements from the websites of UK local government and high street organisations. Quantitative and some qualitative data were gathered and used to reveal information about the nature, content, purpose, audience and execution of the statements, and were also used for a cross-sector comparison.

The selected method had some particular benefits:

- A large survey was a convenient way to find out what website developers and organisations in different sectors were doing with their accessibility statements and offered the opportunity to develop some generalisations about trends.

- A checklist was an easy way to gather a large amount of data to answer multiple issues about statements and was a way of being very precise about the information gathered.

- It was possible with quantitative data to make direct comparisons between sectors.

- The statements were easily available for study. This was an important advantage for a short research project.

- Johnson and Ruppert (2001), had attempted a similar study, but at a lesser depth and with no analysis, and it seemed to be an interesting methodology to develop. 
- The methodology offered some opportunity for comparison with previous research, as quantitative data (e.g. number of statements in a sample of websites) had been gathered in previous studies.

\section{Checklist development}

The questions that formed the checklist were developed after two exercises. The first was an analysis of the contents of some sample accessibility statements. The accessibility statements that were used for content analysis can be found in Table 1. The second was the development of questions based on the issues raised in the literature on accessibility statements and in a joint proposal made by the University of Dundee and Loughborough University for research into accessibility statements. ${ }^{1}$

\begin{tabular}{|c|c|}
\hline Organisation & URL \\
\hline $\begin{array}{l}\text { Sainsbury's } \\
\text { Bank }\end{array}$ & http://www.sainsburysbank.co.uk/savings/info accessibility.shtml \\
\hline Barclays Bank & http://www.barclays.co.uk/accessibility/ \\
\hline Dulux & $\begin{array}{l}\text { http://www.dulux.co.uk/webapp/wcs/stores/servlet/DuluxAccessi } \\
\text { bilityStatementView?storeId=10752\&catalogId=10051\&langId=- } \\
\underline{1}\end{array}$ \\
\hline Ernest Jones & $\begin{array}{l}\text { http://www.ernestjones.co.uk/webapp/wcs/stores/servlet/ernest } \\
\text { jones/accessibility.jsp }\end{array}$ \\
\hline Visit Britain & http://www.visitbritain.com/VB3-en/footer/accessibility.aspx \\
\hline Lastminute.com & http://www.lastminute.com/site/help/accessibility-statement.html \\
\hline $\begin{array}{l}\text { Newcastle } \\
\text { University }\end{array}$ & http://www.ncl.ac.uk/legal/accessibility.html \\
\hline $\begin{array}{l}\text { Salford } \\
\text { University }\end{array}$ & http://www.salford.ac.uk/help/ \\
\hline $\begin{array}{l}\text { London } \\
\text { Borough of } \\
\text { Harrow }\end{array}$ & $\begin{array}{l}\text { http://www.harrow.gov.uk/ccm/content/council-and- } \\
\text { democracy/accessibility.en }\end{array}$ \\
\hline $\begin{array}{l}\text { Herefordshire } \\
\text { Council }\end{array}$ & http://www.herefordshire.gov.uk/accessibility.asp \\
\hline
\end{tabular}

\footnotetext{
${ }^{1}$ Research based on the original joint proposal by the Digital Media Access Group from the University of Dundee has since been published. It offers related data for useful comparison with this study, and provides additional research into the use of accessibility statements by disabled and older people (Sloan et al, 2006).
} 


\section{Table 1: Sample accessibility statements used for content analysis}

A series of questions, many of them open, were placed into an empty answer table that resembled the data gathering table produced by Johnson and Ruppert (2001). The questions were piloted with six accessibility statements from the local government and high street sectors. The pilot demonstrated that the questions were appropriate, but the method of data collection was too open-ended, required too much personal judgement from the data collector, involved considerable amounts of writing and would have created difficulties with data analysis. As a result of this pilot the checklist was re-designed. More of the questions became closed, and the answers became options that could be chosen. This structured checklist was piloted again on six further statements from both sectors. Data collection using the second checklist was found to be much more efficient. At this stage, additional questions were added to the checklist, to avoid unnecessary note making in the 'comments' section at the end, and some questions that were impossible to answer (e.g. 'Has correct structural coding been used for headings, paragraphs and lists, enabling screen readers to make sense of the page?' which could not be answered because it was impossible to view the source code in many instances) were removed. The final, revised checklist was given to another person to test on a sample statement, and comparisons were made with the author's results. It was found that there was little room for subjective differences in response.

\section{The sample}

A sample of 55 local government and 55 high street organisations was chosen to study, to provide a sufficient amount of data to identify trends, similarities and differences between sectors. Local government websites were selected from Tagish Essential Directory of UK Information Sources: County District and Borough Council Websites (Tagish, 2006), and high street websites were selected from British Companies: High Street Stores (n.d.). A random sample of websites from each list was generated using the online tool 'research randomizer' (Urbaniak and Plous, 2006). The checklist was applied to the first 55 sites in each randomised list.

\section{Research findings}

\section{The presence or absence of a statement}

The research uncovered a striking difference between the two sectors in the initial question of whether or not the websites had an accessibility statement. $80 \%$ of local government sites in the sample had an accessibility statement in comparison with only $20 \%$ of high street sites. These findings can be compared with the results of previous research. Petrie, Badani and Bhalla (2005), found even lower results for accessibility statement or logo presence in the e-commerce (4\%) and financial $(12 \%)$ sector, which is directly comparable with the high street sample in this study. They found some clustering of statements amongst certain groups of 
organisations, especially department stores and banks. This study found similar clustering of accessibility statements in bank websites - 5/6 (83\%) of bank websites in the sample had statements, and $1 / 1$ of jewellery websites in the sample had statements. Informal investigation in the development of the study also found many other high street jewellers' websites with accessibility statements. Apart from the clustering of jewellery retailers, this study found low accessibility statement presence for retail stores overall, replicating the low figures for ecommerce in Petrie, Badani and Bhalla's research (Petrie, Badani and Bhalla, 2005). The lowest accessibility statement presence in this study was amongst clothing retailers (1/9) and department stores (1/9).

There was no clear evidence of clustering within the local government sector and there were no particular features connected with the $20 \%$ of local government organisations that did not have an accessibility statement. They were distributed across Britain, and were both small and large authorities (including three city councils; Newcastle, Carlisle and Lincoln). In fact, a small local authority website (Clackmannanshire Council) has recently received praise for high standards in the SOCITM Better Connected report (Champion, 2006), and despite its small budget it has an accessibility statement.

Data in all following sections is taken from the $80 \%$ of local government websites and $20 \%$ of high street websites that had an accessibility statement.

\section{How the accessibility statements were found}

In the literature on how to write accessibility statements, a key feature of good practice that is mentioned is the importance of making the statement easy to locate. Many authors (Burgstahler, 2006; Gibson, 2004; Pilgrim, 2002), recommend placing an accessibility statement either on the homepage, or with clear links from the homepage. Good, clear signposting of the accessibility statement is particularly important because of the accessibility needs of the intended audience of the statement. This section of the checklist looked at the positioning, text size, colour contrast and choice of words for the link to the accessibility statement in order to find out how easy it was to find the accessibility statement.

Poor results in this section were found particularly in the high street sector. They had fewer links from the homepage to the accessibility statement than the local government sector, with only $73 \%$ offering a homepage link in comparison with $91 \%$ of local government websites. $50 \%$ of the high street sector's links to the accessibility statement had a smaller text size than the rest of the text on the page, $50 \%$ had poor colour contrast, and placement of the link was at the bottom of the page more often, in $74 \%$ of cases, making the link less prominent. However, some local government sites also performed badly in this area, as nearly $20 \%$ of their homepage links were in smaller text than the rest of the page and $25 \%$ of their homepage links had poor colour contrast between text and background. These results have serious implications for people who may benefit from the accessibility information; they may not be able to find the statement as a result of this poor signposting and lack of consideration of their accessibility needs. 
Nearly $10 \%$ of local government and nearly $30 \%$ of high street organisations expected the user to search for the accessibility statement on their website, as they buried it within the site without a homepage link and often failed to make it accessible through the sitemap or search facility. Searching for these statements was difficult for a researcher who was committed to finding them, but would be even more difficult for a user with access needs who may already be having difficulty in navigating around the site (without the benefit of the accessibility information!).

In both the local government and the high street websites, the most frequently chosen word for the link to the statement was 'accessibility', with $73 \%$ of local government and $87 \%$ of high street websites choosing this word. 'Access' or 'accessibility' also featured in many of the other links: 'access for all' in the high street, and 'access options', 'accessibility policy', 'site accessibility', and 'accessibility options' in local government (total 13\% for high street and 12\% for local government). This means that 'accessibility' or a derivative was used in $100 \%$ of the high street links and in $85 \%$ of local government links. 'Help' was also used in $10 \%$ of local government cases, e.g. 'help' or 'help about our website'. Alternative phrases for links included 'accessibility help' and 'services for people with disabilities'.

The word chosen for the link to the statement should have relevance to those who would benefit from it, and a mention of disability in the link may prevent many of those potential beneficiaries who "would not consider themselves to be disabled" (AccEase Ltd, 2005, 3), from clicking it.

The concept of access or accessibility, that was so favoured by the high street sector, may have little meaning for many website users, apart from people who are aware of the terminology of disability politics and those involved in webdesign. The connection between 'help' and accessibility in the minds of users of websites may need further investigation, as this was an alternative that was used in the local government sector.

\section{The accessibility of the statement page}

This study conducted some simple manual accessibility tests on the statement page, to identify the two sectors' performance on some of the WAI's 'quick tips to make accessible websites' (Web Accessibility Initiative, 2006). All of the elements are fairly straightforward to produce in practice and can make a considerable difference to the user. The checklist looked at the presence of alt tags that describe the function of images on the accessibility statement page, whether a text equivalent was provided for every non-text element on the page, whether any hypertext link made sense out of context, whether there was good colour contrast between text and background and whether relative font sizes and colours had been used that could be adjusted by the user. The research showed that the local government websites performed comparatively well on all of these tests. This supports previous research into the relative website accessibility of different sectors that shows that government sites tend to perform better in 
accessibility evaluations than retail sites (e.g. Jackson-Sanborn, Odess-Harnish and Warren, 2002).

\section{Content of the statement page}

There are several sources of advice on what to include in an accessibility statement. This advice can be found, for example, in PAS 78 (British Standards Institution, 2006), Burgstahler (2006), Chavan and Steins (2003), Clark (2002), Gibson (2004), Hochheiser and Shneiderman (2001), Pilgrim (2002), Lemon (2005), Phipps et al (2004) and Providenti (2005). Although there is some variation in advice on content, there are several key elements to an accessibility statement that are recommended by many writers. These elements are:

- A statement of assurance / commitment to accessibility.

- An outline of the accessibility features of the site.

- A mention of access keys.

- A statement about web standards compliance.

- An explanation of access problems with a commitment to resolve the issues.

- The details of how to contact the webmaster if problems are encountered.

- Information on how to change the browser settings e.g. text size or colours.

- Links to external tools that may be of assistance.

The research showed that many of the accessibility statements in both local government and high street sectors failed to include these core aspects of a good statement. Only one local government statement (Slough Borough Council) and none of the high street statements included all of these elements. Several local government statements came close, omitting only one element (Cornwall County Council, Newport City Council, Cotswold District Council, Crewe and Nantwich Borough Council, London Borough of Havering, Aberdeenshire Council, Wiltshire County Council), but no high street statements came similarly close. The most comprehensive was HSamuel's accessibility statement, which had five of the core elements. Several high street statements included only one of these key elements (e.g. MFI Homeworks, HSBC Bank).

There was a striking lack of uniformity in the accessibility statements that were studied. Very few of the statements had all of the possible elements presented in a useful way. Observing the data for the statements in both sectors, the number of elements within each statement ranged from a minimalist 3 (e.g. MFI Homeworks, Lancaster City Council) to a comprehensive 13 (e.g. HSamuel, Cotswold District Council).

\section{Audience, language and the social model of disability}

In this study, data was gathered about the audience that the accessibility statements were written for: who the organisations were addressing in their 
statements and which people were mentioned in the statements as recipients of the information. The results were revealing about the concepts that are held about this issue. Even though many people are affected by access needs, including older people, people with situational limitations, for example, people using alternative web-access equipment (Thatcher et al, 2002, 8), and those who would not consider themselves disabled (AccEase Ltd, 2005, 3), the results show that 45\% of high street statements referred to disabled people as the recipients of the information. In contrast, only $27 \%$ of local government statements did the same.

When mentioning individual impairments, there was a heavy emphasis upon visual impairment in the accessibility statements of both sectors, with mention of dexterity issues (e.g. difficulties using a mouse) a common second impairment in the local government statements. Those who use British Sign Language (BSL) and people with cognitive impairments were rarely mentioned. Few accessibility statements mentioned the use of Plain English, despite the fact that its use would assist people with cognitive impairments and hearing impairments or BSL users to access the site.

A broad range of other recipients were mentioned by local government statements, showing awareness that accessibility issues can affect users of handheld devices and those experiencing situational rather than personal accessibility problems (Thatcher et al, 2002, 13). High street statements showed less awareness of this. Local government statements also mentioned a surprisingly wide audience of other people, including those who would not have need for an accessibility statement (the young, parents, those who need translation services). These results demonstrate that there is some confusion amongst writers of statements about the role of an accessibility statement.

The language used to speak about disabled people in the statements in both sectors is revealing about the levels of awareness of the Social Model of Disability, which recommends the use of 'disabled people' rather than 'people with disabilities' (Playforth, 2003, 8). Surprisingly, the high street sector performed better in this respect; local government statements consistently used 'people with disabilities'. Use of this phrase may alienate the proportion of disabled people who are aware of disability politics and social model terminology.

The best statements, however, did not mention 'disabled people' at all or any other audience. They simply mentioned the barriers to access on the site and offered help on how to overcome them. This is in line with social model theory, where emphasis is on removal of barriers in the external world rather than on the impairment of the individual as the problem (Tregaskis, 2002, 460). Many examples of this type of treatment were in the local government sector.

\section{Types and roles of statements}

An analysis of the data for the statements as whole units, and observation of the tone and style of the statements led to the categorisation of the statements in this sample into several functional types. These types were:

- User centered 
- Declarative

- Specialist

- Minimal

- $\quad$ Mixed

The first, 'user-centered' were statements that emphasised practical instructions over policy and focused on problem-solving for the user. $32 \%$ of local government and $37 \%$ of high street statements fitted this category. The second, 'declarative' were statements that made announcements about the site's accessibility, without instructions. They either had a policy focus or used the statement as a way of gaining credit for accessibility work done. $27 \%$ of high street and $14 \%$ of local government were declarative. The third, 'specialist' were statements that contained only material that was unintelligible to those unaware of web-design vocabulary, seemingly aimed at other web-designers. Only a small proportion of local government statements and no high street statements were specialist. The fourth, 'minimal' were statements that were brief, addressing few elements. $3 \%$ of high street and $18 \%$ of local government statements were minimal. The final category, 'mixed' were statements that attempted to take on multiple roles, including combined roles of practical help, policy, disclaimers and others. $34 \%$ of local government and $27 \%$ of high street statements were mixed use.

These figures and observations of the use of statements show that the majority of the statements (68\% of local government and $63 \%$ of high street) were written in a way that were not essentially user-centered. This research demonstrates that organisations are clearly using accessibility statements for many purposes other than to provide the user with instructions. The large figures for mixed use statements also demonstrate that many organisations do not decide to use their statements for one particular function, but for many; they are trying to be 'all things to all people'.

Detailed observation of the content of the statements in the sample showed that the high street statements had more declarations of assurance or commitment to accessibility, but fewer practical instructions. Many of these statements were being used to announce excellence in disability service without taking the opportunity to offer any accessibility support. Local government statements were used more often for practical instructions than the high street statements. The local government sector also used accessibility statements more for announcements about their compliance with the Web Content Accessibility Guidelines (WCAG) developed by the Web Accessibility Initiative, a body of the World Wide Web Consortium (W3C) than high street organisations. When the high street accessibility statements mentioned the $\mathrm{W} 3 \mathrm{C}$, this tended to be to associate themselves with the organisation rather than to state their compliance with the accessibility guidelines. 


\section{Conclusions}

\section{Summary of sector comparison}

This research aimed to examine and compare the website accessibility statements of local government and high street organisations. Considerable difference was found between the two sectors, in whether they had accessibility statements or not, their contents, and the effectiveness of their delivery. The comparisons can be summarised as follows:

\section{High street sector}

- The high street sector appears to be less proactive in considering disability accessibility issues than the local government sector. There appears to be less of a culture of accessibility in the high street sector.

- They had fewer accessibility statements; only a small percentage of tested sites had accessibility statements.

- Many of the high street websites that did have accessibility statements made them difficult to find.

- There were more accessibility difficulties with the statements from this sector.

- There were more poorly executed statements in this sector (e.g. thin statements missing important elements).

- Few high street statements mentioned web standards or WACG and their level of compliance with these guidelines.

- All high street statements failed to mention user testing of their sites.

- They failed to take the opportunity to provide practical help. A large proportion failed to mention changing browser settings or access keys.

- Many failed to provide an option for feedback and most failed to acknowledge current accessibility problems with the site.

- The statements were more often used as a way of declaring their commitment / intentions and affiliations with disability organisations whilst often lacking enough practical help.

- They had more of an emphasis on making 'special' arrangements for disabled people.

- They often put their web accessibility information into a suite of pages about general service accessibility. Grouping their information about accessibility together is useful and could be something that the local government sector could learn from.

\section{Local government sector}

- There appears to be more of a culture of recognising disability accessibility issues in the local government sector. 
- There were many more accessibility statements in the local government sample.

- They were better at highlighting the existence of the statement on their websites.

- The statements from this sector were more accessible.

- More of the statements from this sector were comprehensive, containing more of the 'essential elements' recommended by writers of advice.

- There was more practical help in these statements. Many of them mentioned access keys and a large proportion mentioned changing browser settings.

- However, most local government sites failed to mention user testing.

- Most failed to mention any links with disability organisations.

- Most failed to acknowledge current accessibility problems with the website.

\section{Recommendations for a good accessibility statement}

The following recommendations are synthesised from the advice provided in the literature on accessibility statements and analysis of the best and worst statements in the samples that were studied. Further research could test these recommendations against possible users of accessibility statements, to see if they do provide an effective accessibility statement.

\section{Access}

- Ensure that the statement is clearly signposted, with links from every page, especially the homepage.

- Make the links to this statement clear and apparent. Put them at the top of the page, with clear colour contrast and good size.

- Use a practical, solution-orientated phrase for the link. Avoid 'disability' and 'accessibility'. Consider a "how to" phrase instead.

- Make your statement page accessible. Remember to make the rest of your site accessible too - people will be using the whole site, not just the accessibility statement.

\section{Content}

- Include, if you want to, a statement about how important accessibility is to your company. But do not just leave it at that. Include as a minimum:

- Practical instructions about how to use the accessibility features on the site, including access keys, browser changes and instructions on how to navigate around the site;

- Information and links to tools that can help the user to get the most from the site; 
- An acknowledgement of current accessibility problems with the site and an explanation of how users can access the content in an alternative way;

- Contact details that connect directly with the webmaster rather than a general customer service point. Encourage users to report accessibility difficulties with the site and include a commitment to resolving these difficulties;

- Details of compliance with guidelines (but explain the meanings of this clearly and do not make this the first thing that you mention).

- Avoid writing about what you have done to make the site accessible. Instead focus on the solutions for the user.

- Do not include extra, irrelevant material (such as opening hours) in the statement.

\section{Audience, language and style}

- Write the statement for the user of the website, not for other web designers or policy makers.

- Write the statement for a broad audience base, including older people. Avoid writing just for disabled people.

- Remember that access issues cover a broad spectrum of areas - do not only write for visually impaired people or people who cannot use a mouse.

- Keep it really simple - use simple language and plain English.

- Avoid specialist terminology at all costs - something that you consider easy to understand may not mean anything to the reader.

- Write it directly to the user who is facing accessibility difficulties with your website. Use phrases like "if you want to make the text bigger ..." "if you need to listen to the text..." rather than "changing browser settings."

- If you need to write about people with impairments, use "disabled people" rather than "people with disabilities" or "the disabled" - this is in line with the Social Model of Disability.

\section{Presentation}

- Avoid one really long paragraph for your statement. Divide the text into clearly headed paragraphs. Make sure that each paragraph contains only one idea.

- Use visual clues or pictograms for each paragraph for easy identification of the contents by users with reading or concentration difficulties.

- Put practical instructions first and make them the main focus on the page. Sideline other information by putting it in a separate section on the page, or by creating a link for further information. 
- Put links to every section of the statement at the top of the page, to enable users to quickly jump to the section they need. Make the links meaningful and simple.

- Use diagrams and / or screenshots to explain how to change browser settings.

- Consider providing 'instant buttons' that generate an immediate change in text size or text / background colour.

\section{Recommendations for further research}

This research has opened up several areas of potential research. Further study could be undertaken in the following areas:

- Significant differences were found in the presence and execution of statements in the high street and local government sectors. Further research could attempt to uncover the reasons behind the difference between the sectors and establish ways to improve performance.

Questions include: What factors are involved with the decision to include a statement? What reasons are behind the clustering of statements in one sector and not in another? Of those organisations who do not have statements on their websites, why not?

- This study has looked at the accessibility statements of the high street and local government sectors. Further research could replicate the study in other sectors (e.g. higher education, voluntary sector) and make comparisons with the findings from this study.

- There is a lack of knowledge about accessibility statements from the perspective of the possible user. Further research with people with website access needs could answer many questions and test presumptions articulated by designers in discussion forums (e.g. that few people read accessibility statements, that an accessible site can easily be used without explanation, that people find accessibility help condescending).

- Research is also needed into the meaning of 'accessibility' to people with access needs, into their understanding of what an accessibility statement is and what it can be used for and the concepts that are raised in statements. Would they consider looking at a site's help page for similar advice, and is there is any connection between help and accessibility in their minds?

- Forum discussions suggest that there are mixed opinions about the value of accessibility statements amongst web designers. Further research could investigate in more detail the attitudes towards and mental concepts of accessibility statements amongst this group. Also what type of help for writing statements would they like to see?

- There is little mention of accessibility statements by official bodies and writers of advice for accessible web design. Further research could ask them about their opinions or positions on accessibility statements. Do they consider them to be useful? What is the reason for their near-silence on 
the topic? Would they consider including advice on statements in the future?

- Petrie, Badani and Bhalla (2005) found that sites with accessibility statements were no more accessible than those without statements, but untested observations when gathering data for this study questioned that finding. What is the relationship between accessibility statement presence and website accessibility?

\section{References}

AccEase Limited (2005) Bridging the digital divide: how are government websites meeting the accessibility needs of users? A survey of 150 government agency websites for the Office of Disability Issues. URL:

http://www.odi.govt.nz/documents/publications/bridging-the-digital-divide-nov2005.pdf [accessed 12.4.06].

British Companies: High Street Stores (n.d.) URL:

http://www.britishcompanies.co.uk/highstreet.htm [accessed 25.5.06].

British Standards Institution (2006) PAS 78: 2006. Guide to good practice in commissioning accessible websites. URL:

http://www.drc.org.uk/library/website_accessibility_guidance/pas_78.aspx [accessed 26.09.07].

Burgstahler, S. (2006) Web accessibility: guidelines for busy administrators. Handbook of Business Strategy [online], 7(1), 313-318. URL: http://www.emeraldinsight.com/Insight/viewContentItem.do?contentType=Article $\underline{\text { \&hdAction }=1 \text { kpdf } \& \text { contentId }=1523742}$ [accessed 10.8.06].

Champion, D. (2006) Why size doesn't matter in setting web standards. The Guardian [online], 29 March. URL: http://society.guardian.co.uk/epublic/story $/ 0,1741315,00 . h$ tml [accessed 10.05.06].

Chavan, A. and Steins, C. (2003) Doing the right thing. Planning [online], 69(7), 10-13. URL:

http://proquest.umi.com/pqdweb?did=379258791\&Fmt=3\&clientId=5238\&RQT= 309\&VName=PQD [accessed 30.6.06].

Clark, J. (2002) Building accessible websites. Indianapolis: New Riders Publishing.

Gibson, L. (2004) Writing an accessibility statement. URL:

http://www.dmag.org.uk/resources/design_articles/accessibilitystatement.asp [accessed 30.8.06].

Great Britain (1995) Disability Discrimination Act 1995 (c. 50). URL: http://www.opsi.gov.uk/acts/acts1995/1995050.htm [accessed 30.8.06].

Hochheiser, H. and Shneiderman, B. (2001) Universal usability statements: marking the trail for all users. Interactions [online], 8(2), 16-18. URL: 
http://portal.acm.org/ft_gateway.cfm?id=1037130\&type=pdf\&coll=ACM\&dl=AC M\&CFID=486951\&CFTOKEN=79021637 [accessed 24.6.06].

Jackson-Sanborn, E., Odess-Harnish, K. and Warren, N. (2002) Web site accessibility: a study of six genres. Library Hi Tech [online], 20(3), 308-317.

URL:

http://www.emeraldinsight.com/Insight/ViewContentServlet?Filename=/publishe d/emeraldfulltextarticle/pdf/2380200306.pdf [accessed 23.04.06].

Johnson, A.M. and Ruppert, S. (2001) Known campus statements on web accessibility. URL: http://www.uwosh.edu/accessibility/papers/campuses.htm [accessed 25.7.06].

Lemon, G. (2005) Writing a good accessibility statement. URL:

http://juicystudio.com/article/writing-a-good-accessibility-statement.php [accessed 10.05.06].

Petrie, H., Badani, A. and Bhalla, A. (2005) Sex, lies and web accessibility: the use of accessibility logos and statements on e-commerce and financial websites. Paper presented at the Accessible Design in the Digital World Conference, 23-25 August 2005, Dundee, Scotland. URL:

http://www.bcs.org/server.php?show=ConWebDoc.3803 [accessed 16.09.07].

Phipps, L. et al (2004) Developing and publicising a workable accessibility strategy. Ariadne [online], (38). URL:

http://www.ariadne.ac.uk/issue38/phipps/intro.html [accessed 30.5.06].

Pilgrim, M. (2002) Dive into accessibility: 30 days to a more accessible website.

Day 30: creating an accessibility statement. URL:

http://diveintoaccessibility.org/day_30 creating_an accessibility_statement.html [accessed 10.8.06].

Playforth, S. (2003) Meeting disabled people. London: Resource: The Council for Museums, Libraries and Archives.

Providenti, M. (2005) The art of the accessibility statement. Internet Reference Services Quarterly 10(1), 47-62.

Sloan, D., et al (2006) Evaluating the usability of online accessibility information. URL: http://www.techdis.ac.uk/index.php? $\mathrm{p}=3 \quad 10 \quad 10 \quad 1$ [accessed 30.8.06].

Tagish (2006) County, district and borough council websites. URL: http://www.tagish.co.uk/links/localgov.htm [accessed 27.6.06].

Thatcher, J. et al (2002) Constructing accessible websites. Birmingham: Glasshaus.

Tregaskis, C. (2002) Social model theory: the story so far... Disability \& Society [online], 17(4), 457-470. URL:

http://taylorandfrancis.metapress.com/media/07wck7ce3mdyuld07aak/contributio ns/u/l/d/3/uld3bgutuvd962wq.pdf [accessed 29.8.06]. 
Urbaniak, G.C. and Plous, S. (2006) Research randomizer. URL:

http://www.randomizer.org/ [accessed 12.4.06].

Web Accessibility Initiative (2006) Quick tips to make accessible websites. URL: http://www.w3.org/WAI/References/QuickTips/ [accessed 30.8.06].

World Wide Web Consortium (1999) Web content accessibility guidelines. URL: http://www.w3.org/TR/WAI-WEBCONTENT/ [accessed 30.8.06].

\section{The Occasion}

This article summarises the dissertation 'Website accessibility statements: a comparative investigation of local government and high street sectors' that was completed as part of the MA in Information and Library Management at Loughborough University. The author was awarded the LIRG postgraduate prize 2007 for this dissertation.

\section{Acknowledgements}

The author acknowledges the help and support of her dissertation supervisor, Wendy Olphert, and her personal tutor, Ann O'Brien. Thanks also to David Sloan and Anna Dickinson of the University of Dundee and Wendy Olphert of Loughborough University who developed the original research proposal that provided the stimulus for this study. 